Artículos

\title{
TIJUANA. LA FRONTERA CONCUPISCENTE Y EL COMIENZO DE LA PATRIA
}

\author{
Rogelio E. Ruiz Ríos
}

Resumen: Este texto forma parte de un avance de investigación en curso que se propone centrar en su debido contexto histórico la discusión de las ideas y del sustrato ideológico que delinean tres de las principales representaciones sociales que hoy día gravitan sobre la ciudad de Tijuana. Se parte del hecho de que las nociones sobre el carácter de esta localidad, configuradas a lo largo del siglo $\chi X$, impactan en el imaginario nacional e internacional y atraviesan aspectos políticos, sociales, artísticos, mediáticos y académicos. Este conjunto de imágenes resultantes que intentan dar cuenta de Tijuana es transversal a los conceptos de frontera, norte mexicano, cultura nacional, patria y globalización.

Palabras clave: Tijuana, frontera, nacionalismo, centralismo, imaginario social, cultura local

Enviado a dictamen: 21 de julio de 2009

Aprobación: 25 de octubre de 2009

Revisiones: 1

Rogelio E. Ruiz Ríos, doctor en historia por El Colegio de Michoacán, A.C., adscrito al Instituto de Investigaciones Históricas de la Universidad Autónoma de Baja California, temas de especialización: Historia social, colonización extranjera en México, nacionalismo y estudios sobre fronteras, Instituto de Investigaciones Históricas. Correo electrónico: aukaroger@hotmail.com.
Abstract: This paper, like a part of an ongoing investigation, is focused on the historical context and the ideas and ideological substrate that delineate, may be are the three main social representations that gravitate on the city of Tijuana. The existing notions about the nature of this city, set along the twentieth century, affect on the national and international social imaginary, and reach diverse topics as the political, social, artistic, academic, and media issues. The set of images produced on Tijuana is cross-cutting by notions offrontier, northern Mexican, national culture, globalization and homeland.

Key words: Tijuana, border, nationalism, centralism, social imaginary, local culture.

\section{Introducción}

E siguiente texto es un primer avance de una investigación más ambiciosa sobre algunas de las representaciones sociales históricamente construidas en torno a la ciudad de Tijuana. En primera instancia, aquí se alude al contexto ideológico en el cual se intenta producir tradiciones en Tijuana, una tarea que asumen principalmente ciertos sectores ligados a las esferas políticas, empresariales y culturales, erigidas en garantes de un pretendido legado moral y social traído del pasado. Esta posición es legitimada a través de relatos históricos institucionalizados mediante rituales 
cívicos que las validan frente a la comunidad. Para tales efectos, se precisa exhumar, inventariar y cribar el pasado y compaginarlo con los propósitos perseguidos por quienes validan el conocimiento resultante.

En un segundo ámbito, a partir de la construcción de la celebración fundacional de Tijuana, se analiza y describe el origen del poblado en el concierto de las tensiones sociales y el dinamismo económico que proyecta su condición de frontera. Se abunda en la brecha que hay entre las narraciones históricas oficiales y una interpretación crítica de los procesos que la fundamentan. La discusión se ubica el análisis de las prácticas, discursos, símbolos y representaciones desplegadas en las relaciones entre los representantes de una visión centralista del Estado mexicano y la de quienes se invisten como portadores de sentires locales y regionales, posición que los coloca en la disyuntiva de favorecer, condicionar, rechazar o adaptar las propuestas del centro según sus intereses particulares.

\section{Tendencias asépticas tras la búsqueda local de legitimidad ante el exterior}

En Tijuana es palpable la necesidad de inventar tradiciones. Detrás de esta inquietud yace la pretensión de perfilar una imagen de la ciudad contrapuesta a las representaciones peyorativas que históricamente le han sido endilgadas. Por lo común, las representaciones sobre Tijuana proyectadas al interior y exterior de la comunidad, la sitúan como un espacio latente para el florecimiento de un amplio abanico de hechos ilícitos y actos proscritos en lo moral, lo ético y lo jurídico. La ciudad es blanco de leyendas que gustan de describirla como un imán concupiscente, dotada de un magnetismo capaz de atraer un enjambre de sibaritas dispuestos a reproducir las experiencias que la han edificado como escenario habitual del escándalo moral y la nota roja.

No extraña que concepciones tan poco lisonjeras generen reacciones en contra de grupos e individuos quienes, con intenciones asépticas, buscan combatir los enormes molinos de viento que soplan a favor del estigma de disipación históricamente ceñido sobre la ciudad. Al frente de estas iniciativas destacan pequeños grupos tendientes a mostrarse bajo las etiquetas de "opinión pública", "sociedad civil" o "tijuanenses". Esto explica el por qué cuando un escritor local como Gabriel Trujillo Muñoz (2005), valiéndose de aforismos, intenta hacerse el gracioso a costa de los estereotipos pendientes sobre la ciudad. ${ }^{1} Y$ es que así se trate de una ocurrencia literaria, es bastante temerario afirmar, como lo hace este escritor, que en Tijuana cada mujer representa una prostituta en potencia.

Paralelo a esta clase de delirios "literarios", circulan varias expresiones que otorgan a la ciudad un talante violento, decadente, venal. A lo anterior, se yuxtapone la imagen de que esta condición enajenante también engendra una ciudad vibrante, efusiva, transgresora, laboratorio de identidades, multicultural. Una urbe erigida como bisagra entre el primer y el tercer mundo; entre el norte y el sur, donde Latinoamérica inicia. Cuna a la vez de un florecimiento artístico y cultural singular en México. Tal perspectiva alcanzó su paroxismo en el proyecto multidisciplinario "Tercera Nación", auspiciado por el empresario Antonio Navalón vinculado al corporativo Prisa. ${ }^{2}$

Los habitantes de Tijuana, día a día se percatan que junto a las notas periodísticas locales, prestas a describir la miríada de actos violentos acaecida la noche previa, se publican declaraciones y proyectos tendientes a enseñar "la otra cara" de la ciudad. A menudo, este sumario de buenas intenciones es suscrito por agrupaciones en cuya denominación llevan la penitencia: "Unidos por Tijuana", "Tijuana opina", "Tijuana en marcha" o "Tijuana renacimiento". Por lo regular, al frente de estos membretes destacan personajes ligados a los medios empresariales y políticos. La mayor parte de estas campañas de higiene moral y social se reduce a actos publicitarios, aderezados en ocasiones con una buena dosis de chovinismo regional.

En algún punto, las campañas en pro de limpiar la imagen de Tijuana se entreveran con la reivindicación 
de un pasado ajeno que se presupone fue mejor que la situación actual. Ante un presente enmarcado dentro de elevados índices de inseguridad, violencia social, atentados al pudor y relajamiento de los "valores familiares tradicionales". Así, el pasado expuesto a través del relato histórico tomado como oficial y veraz, es contrapuesto como ejemplar, y por ello imitable, hacia las generaciones contemporáneas. Esto conlleva someterlo a manipulación en tanto auxiliar en el fortalecimiento de la cohesión social, la generación de lealtades y dador de legitimidad social y moral a quienes se ostentan garantes del culto a ese pretérito.

Con el propósito de extender cierto ideal de "comunidad", se busca construir una clase de ciudadano, eficaz contribuyente fiscal, que se sienta identificado con los símbolos y figuras retóricas proyectadas en los relatos históricos vinculadores del presente con el pasado. Para ello, se precisa realizar un inventario histórico de los hechos y personajes que ayuden a legitimar y justificar la imagen oficial que desde esferas gubernamentales y empresariales se busca plasmar sobre la comunidad, al constituirse como la única posibilidad de salvar los problemas contemporáneos. Se trata de una propuesta identitaria cuyo afluente ideológico es el sistema de ideas y valores políticos, sociales y culturales compartido por los grupos ligados al ejercicio del poder político y económico.

Garantizar la hegemonía de todo proyecto político y social requiere apoyarse firmemente en un sistema religioso y educativo que naturalice el orden o sistema ofrecido. El éxito de la propuesta ideológica en juego, sujeta a su vez a un entramado de relaciones jerárquicas forjadas en el exterior, necesita arraigar entre las nuevas generaciones. De ahí que sea imperativo que la capacidad de autoridad y sanción del pasado se instile en la mente de los niños, que se erija frente a ellos en "el único esquema conceptual del mundo y de las normas morales de conducta" (Bell, 1989: 68). Aún en la modernidad, no dejan de edificarse tradiciones sustentadas en la autoridad del pasado, cuya lectura es determinada según los cánones sociales predominantes.
La promoción de una particular interpretación de la historia privilegia que se difunda entre niños y jóvenes. Esta dinámica es visible en Tijuana, cuya agenda social y cultural está marcada por la urgencia de inventar tradiciones en aras de inculcar "arraigo" y generar "identidad" en las nuevas generaciones. Eventos organizados con participación del sistema educativo estatal como el concurso de historia local dirigido a estudiantes de primaria o la feria de historia de la ciudad a los adolescentes de secundaria, responden a tales premisas. Plantearse las cosas en este sentido, supone preguntarse si acaso esta expresión de la modernidad que acude a la historia como fuente de legitimidad y afirmación de cierto estándar de ideas y percepción del mundo, sólo reclama la intervención de los grupos hegemónicos o también involucra la participación de grupos subalternos y de ser así, en qué forma lo hacen.

Aunque ahondar en la cuestión rebasa por mucho los fines de este escrito, ya que aventurar respuestas implica fundamentarlo en evidencias empíricas que atañan a casos particulares (lo cual es uno de los objetivos contemplados en el futuro desarrollo de la presente investigación), hay que mencionar que desde disciplinas como la sociología, la antropología social y política, los estudios culturales y los poscoloniales, la contestación pareciera obvia. En el campo de estudio de lo social y lo cultural, el empuje gestado a partir de la década de 1960 ha establecido que los grupos subalternos están lejos de permanecer pasivos en la construcción de los procesos y fenómenos que moldean sus relaciones entre sí, con los otros, con los objetos y con lo entendido por naturaleza. Que estos grupos colocados en una posición de inferioridad en el entramado de relaciones jerarquizadas, anteponen una serie de estrategias que dan una diversidad de significados, inmersos en cálculos racionales, a las directrices establecidas por los grupos dominantes. Sin embargo, estas reapropiaciones simbólicas y materiales apenas lograrán o buscarán subvertir el orden social imperante. 
Para acercarse a este tipo de tensiones y mediaciones sociales, junto con los fenómenos resultantes, es pertinente acudir al término de ideología en tanto recurso que permite mayor solvencia teórica. Conviene por ello, revisar algunas de los significados más aceptados que al uso del concepto se le ha dado. En la tradición marxista construida a partir de la segunda mitad del siglo XIX, la ideología fue visualizada como un velo que encubría, mantenía protegida y moldeaba la percepción social de una realidad, de un orden o un sistema en el que los individuos se desenvolvían en comunidad. Es decir, tenía una concepción negativa (Larraín, 2008: 9). Refería a una "falsa" conciencia (Roucek, 1963: 671). Más tarde, con las aportaciones de autores como Plejanov, Kaustky y sobre todo Lenin, el concepto adquirió un sentido "neutro", al concebirse que todas las clases sociales fueran poseedoras de un paradigma ideológico (Larraín, 2008: 34-35).

En esta última perspectiva se sitúa el trabajo de Karl Mannheim, quien sin desconocer la matriz marxista, también abrevó de la fenomenología al precisar lo que hasta Lenin se había sugerido pero no profundizado, que las ideologías no sólo debían entenderse basadas en intereses económicos. Acorde a Mannheim, al desbordar el dilema entre verdaderas o falsas, las ideologías representaban una determinada perspectiva, ya sea fijada por la afiliación a un partido, una clase o una generación, explicable a través del punto particular de cada caso (Roucek, 1963: 685). El significado otorgado por Mannheim, se relaciona con los fundamentos teóricos de la sociología del conocimiento de mediados del siglo XX, enfocada en estudiar la forma en que el conocimiento dependía de la posición social del individuo, de ahí que no se circunscribiera a clases económicas sino también a grupos en función de su estatus, ocupación y rango generacional (Roucek, 1963: 666).

Una acepción distinta a las anteriores provino de Michel Foucault en su Arqueología del saber, quien introdujo en esta discusión el término de "apropiación" al referir que los discursos eran sometidos a una "apro- piación social" a cargo de individuos e instituciones que de esa manera podían someter y confiscar los discursos para así arrogarse su control exclusivo (Chartier, 2005: 52-53; Möller, 2001). Una sugerencia de este tipo permite incluir en la elaboración de discursos la intervención de actores sociales, de diverso origen y estatus, los cuales toman posición en ciertos espacios, sin que necesariamente concentren el poder económico y político toda vez que no están en posibilidades de rebasar el marco social interpretativo que define las condiciones desiguales imperantes. Con mayor amplitud esto es definido por el pensador francés al aseverar que "en cualquier cultura", "hay siempre una sola episteme que define las condiciones de posibilidad de todo conocimiento", esto conduce a un ordenamiento general de lo empírico" (Foucault, 1984: 199-200).

En cambio, en la hermenéutica de Ricoeur, la "apropiación" es pensada en términos de interacción textual con una incidencia estratégica que provee de recursos a los individuos para adaptarse a un contexto cambiante, toda vez que en "el momento en que la 'aplicación' de una configuración narrativa particular a la situación del lector refigura su comprensión de sí mismo y del mundo, y por lo tanto su experiencia fenomenológica tenida por universal y apartada de toda variación histórica" (Chartier, 2005: 53; Möller, 2001).

Chartier (2005: 52-53) se desmarca de la postura de Foucault y del enfoque hermenéutico al proponer una reformulación del concepto de "apropiación" capaz de dar cabida a una pluralidad de usos y entendimientos de la cultura. Lo que se plantea es acentuar "la pluralidad de empleos y de comprensiones y la libertad creadora", aún cuando esté reglamentada, de los agentes sociales distantes de los textos y las normas. (Chartier, 2005).

El historiador francés, desde su reconocida deuda con Michel Certeau y su obra La invención de lo cotidiano, busca entender la apropiación a partir de una historia social de los usos y las interpretaciones relacionadas con sus determinaciones fundamentales, e inscritos en las prácticas específicas que los construyen. Es de 
la opinión que sólo así se atienden las condiciones y los procesos concretos implícitos en las operaciones productoras de sentido. Lo anterior supone reconocer, en contra de la vieja historia intelectual, que ni las ideas ni las inteligencias están desencarnadas. Ello también se opone a las estimaciones de los pensamientos sobre lo universal, al plantear que las categorías dadas de manera invariante, sean fenomenológicas o filosóficas, tienen que pensarse en la discontinuidad de las trayectorias históricas. Así, el concepto de "apropiación" queda ligado estrechamente a los términos de ideología y cultura al proporcionar recursos de argonauta que lleven a una visión profunda en la explicación de los procesos sociales.

Para los fines del tema que da origen a este texto, encontramos pertinentes las reflexiones propuestas por Mannheim en torno al concepto de ideología, matizadas con el concepto de "apropiación social" especificado por Chartier y el papel sociocultural activo de los subalternos que posibilita el enfoque hermenéutico. Este posicionamiento teórico brinda instrumentos para aprehender la complejidad textual y contextual derivada del entramado de intenciones, propósitos y parámetros culturales en los que se fundan las prácticas discursivas de políticos, empresarios, comunicadores y académicos, principales protagonistas de las discusiones en torno a lo que se designa como "Tijuana" y la terminología que de ahí se desprende, sea "lo tijuanense", la "tijuanidad" o cualquier otra forma de identificación que se le adjudique.

Lo anterior debe enmarcarse en las relaciones tejidas entre tres instancias: lo local, lo regional y lo nacional, demarcadas por la "condición fronteriza" de la ciudad, que en la práctica equivale a su "naturaleza". Esto nos conduce al tema de los vínculos entre el centro y lo que se reconoce como sus márgenes, periferias, provincias, o que a veces de manera eufemística se designa como "sus" regiones dentro de la lógica de la comunidad nacional imaginada (cfr. Anderson, 2005). Situar en esta disyuntiva la cuestión de las represen- taciones históricas de Tijuana, abre la posibilidad de acceder a las tensiones y conflictos surgidos entre los agentes de las sociedades locales y regionales y los delegados o vicarios de las instancias nacionales junto con sus presupuestos "integradores", "asimiladores" y "homogenizadores". Las prácticas y formulaciones surgidas de estas interacciones y contradicciones son orientadoras de los íconos que nutren el imaginario social y sus caracterizaciones sobre Tijuana.

En gran medida, debido al auge tenido en occidente sobre los estudios de globalización y sus repercusiones en los temas de investigación planteados desde los estudios culturales y el conjunto de disciplinas sociales y humanas, la idea de que las sociedades de frontera proporcionan un espacio privilegiado para el estudio de los vínculos entre lo local y lo nacional ha derivado en un axioma. El de la frontera concebida como un espacio de constante interacción con lo que política y culturalmente ha sido delimitado como lo otro, lo extranjero, lo no-propio, lo diferente.

Para el caso mexicano, este tipo de lecciones sobre las realidades fronterizas presupone dos lecturas. Una que despierta sospechas sobre la lealtad de los fronterizos al sentido de pertenencia a la nación, según la perspectiva de quienes se asumen representantes del epicentro nacional. Detrás de este tipo de cuestionamientos o interpelaciones se halla en juego la hegemonía del Estado moderno, concebido como expresión y sistematización racional de las inquietudes de lo "nacional". ${ }^{3}$ Por definición, una organización política, jurídica y social de tales pretensiones, requiere de un centro reconocido como síntesis de lo nacional, que a la vez se arrogue facultades para dictaminar los contornos de la nación, de sus referentes significativos y del simbolismo desplegado para producir sentimientos de pertenencia hacia su seno.

Según observó Foucault, detrás de tal enjundia se halla la burguesía, la cual "hizo de la nación el objeto y sujeto de su historia a partir del siglo XVIII" (2002: 198). Para que una nación exista, se precisa de "leyes explíci- 
tas e instancias que las formulen", además del desarrollo de una economía, profesiones liberales y "funciones" a las que Foucault designó como "aparatos": ejército, iglesia, justicia, administración (Foucault, 2002: 199200). Una vez inculcado, arraigado y aceptado, en su mayoría, este sistema político-jurídico de organización social, las tensiones y disputas entre el centro y sus periferias por el control de los símbolos de lo nacional, o por ser incluidos y reconocidos dentro de esta categoría, son objeto constante de debate. Así, emergen discursos y prácticas encaminadas a ofrecer, defender, rechazar o reformular la identidad nacional en diálogo con lo regional y local apelando a condiciones como el origen étnico, de género y clase. Con el transcurso del tiempo, esto trasminó el imaginario social respecto a aquello que se entiende como frontera, cultura, nación, región y comunidad.

Una segunda lectura sobre las fronteras mexicanas está dada como respuesta que pretende emic de aquellos que se sienten interpelados por los cuestionamientos a su afiliación y lealtad nacional. En este sentido, la respuesta también la reivindican sectores burgueses, aunque no es exclusivo de ellos, que reviran las inquisiciones de sus detractores al apuntalar un mayor grado de fidelidad a la nación al hallarse en cotidiana confrontación con lo otro. Es bajo estas coordenadas ideológicas en las que debe situarse la noción de frontera que atañe a las representaciones sobre Tijuana.

\section{Donde inicia la patria}

En el inicio de este texto se señalaba la necesidad de inventar tradiciones en Tijuana como un recurso para "limpiar" la imagen de la ciudad o de contrarrestar la forma en que suele ser representada en y hacia el exterior. Dichas actitudes corren parejo a los propósitos de fortalecer la "identidad" de los tijuanenses, de promover su arraigo y amor por su tierra. Ello implica asumir la creencia de que por décadas, los residentes de la ciudad han constituido una especie de avanzada nacionalista, un contrapeso al expansionismo estadounidense, a la vez que (y he aquí claros visos de ironía), se aprovecha la vecindad con el sur de California, el estado más rico del país más poderoso en el mundo, para erigirla en plataforma cosmopolita de México, que hacen de Tijuana una ventana abierta a la globalización. La asunción de tales criterios queda desplegado en el lema oficial de la ciudad: "Aquí empieza la patria".

La idea de frontera planteada dentro de estos criterios que ven la frontera como un puente más que una barrera, comparte algunas similitudes con la concepción que en las últimas décadas le han atribuido autores como Balibar, Beck y Bauman, a la par de términos como globalización, cosmopolitismo, policentrismo e hibridez. Estamos ante el llamado "giro espacial", proclive a inscribir las fronteras en un mundo dinámico que asiste al decantamiento del Estado-nación. Una cadena de escenarios compuestos por flujos, redes y movilidades transformadores del sentido tradicional de las fronteras (Rumford, 2006).

Ahora bien, la concepción de frontera que más se reproduce y emplea en Tijuana es la que comparten los grupos de tendencias asépticas que según convenga, se mueven entre el sentido tradicional o el posmoderno. En su afán de legitimar sus posicionamientos discursivos, acuden a la historia para darle una función instrumental. Su aspiración es que la historia les permita legitimar las tendencias que buscan imponer mediante su oficialización. Dentro de esta operación, gustan de prescribir la "esencia" de la ciudad y de su parte constitutiva: lo "tijuanense". El relato histórico les brinda la soldadura que articulará las diferencias sociales y culturales existentes entre la población. Mediante textos crean y ordenan el contexto.

Lo anterior se aprecia en los escritos de presentación de un libro editado en 1989 por el ayuntamiento de Tijuana y la universidad estatal de Baja California, en conmemoración al centenario de la ciudad (Ortiz y Piñera, 1989: XIII-XIX): 
En la claridad y orden cronológico del discurso histórico, encuentra su lugar cada una de las múltiples aportaciones de ese mosaico cultural que representa la frontera norte de México, y que los antiguos y nuevos habitantes van haciendo en el devenir histórico y en la conformación de su espacio, para que la identidad de una comunidad se fortalezca como conciencia histórica.

Alfredo Félix Buenrostro Ceballos

Rector de la Universidad Autónoma de Baja California

El ser trinchera y atalaya de nuestra cultura en el extremo noroeste de México y en la cuenca del océano Pacífico...hace que nuestra responsabilidad de ser frontera crezca y nos exija plena conciencia de nuestra identidad, arraigada en las particularidades de nuestro espacio y nuestra historia, pero proyectada a lo universal.

Federico Valdés Martínez

Presidente municipal del XII Ayuntamiento de Tijuana

La retórica presentada trasluce una concepción de Tijuana sostenida bajo las siguientes premisas: 1) es un mosaico de la mexicanidad; 2) es la última trinchera de defensa del orgullo patrio y resguarda la integridad nacional; 3) es puerta de tránsito entre el interior del país y el exterior; 4) constituye un espacio privilegiado debido a su condición fronteriza con Estados Unidos, lo que además, le brinda su toque de cosmopolitismo. Una vez lograda la aceptación tácita de estas características que buscan definir y hablar por la ciudad, quedará delineado un molde para el ciudadano investido con la casaca identitaria que los grupos hegemónicos buscan extender y controlar. De este modo, aceptados por la mayoría de la población, sus proyectos sociales, económicos y políticos podrán etiquetarse como "intereses comunes". ${ }^{4}$

Este modelo discursivo que intenta describir una comunidad, ofrecido por igual a grupos hegemónicos y subalternos, promete un porvenir compartido. Por ende, demanda unidad, solidaridad y simpatía ante los "desafíos" que en el presente y futuro deparan a la colectividad. El éxito de esta apuesta dependerá de las lealtades, cohesión social e inmutabilidad de la estructura de las relaciones sociales prevaleciente. ${ }^{5}$

Guardada toda proporción, lo que estas prácticas permiten constatar es la reproducción a escala local o comunitaria de la búsqueda o consolidación de una modernidad inacabada usual a una sociedad alejada de los centros donde se monopolizan y reparten las funciones y militancias de una nacionalidad. A gran escala, podríamos citar la historia de los estados nacionales postcoloniales, cuyos siglos XIX y XX están plagados de ejemplos. Con acierto, Renato Ortiz ha señalado que "en América Latina la construcción de identidad se vinculó siempre a la búsqueda de la modernidad". 6 Claro que existen múltiples modernidades, según el contexto desde el que se hable.

Emplear los términos de proporción y escala no es un mero recurso estilístico. Entraña un planteamiento metodológico, integrado a la profesionalización y afán de cientificidad de las disciplinas sociales y humanas, forjado desde fines del siglo XIX. La "comunidad" se convierte en una muestra de unidad de observación para el estudio de la cultura o la sociedad, es un locus o encarnación local de lo social como un fenómeno más amplio. Es el terreno de prueba de lo general.

Para Conrad Arensberg, una comunidad es representativa en tanto cuenta con una composición plural en cuestiones de género, clase, estatus, generacional, credos, grupos étnicos, y por tanto, puede ser utilizada para arrojar preguntas a interrogantes sobre "problemas" de impacto más amplio. Debe además presentar repeticiones y continuidades de forma que se puedan construir series, lo mismo que fisiones dentro de esta misma continuidad (Arensberg, 1961: 255 y 260). Puesto en estos términos, Tijuana se vislumbra como una comunidad que permite aproximarse a una situación frecuente en la historia de las relaciones entre el poder 
nacional y las sociedades de la frontera norte mexicana. Se asumen, la presencia de una forma de estructura que consta del regateo por la nacionalidad, desde el centro hacia los pobladores fronterizos, y las correspondientes pruebas de lealtad y de edificación moral con que se suelen contestar esas afrentas.

Este es el marco donde tiene que ubicarse la urgencia por inventar tradiciones en Tijuana, a modo de arrojar elementos que ayuden a fabricar un molde que contenga lo "tijuanense". La tradición haya su fuerza coercitiva en el pasado. Por ello, el pasado se somete a un inventario. Se instrumenta un proceso de selección de aquellos pasajes que refuercen el discurso histórico oficializado como "verdadero". Al mismo tiempo, se va poblando un panteón de hombres ilustres (y alguna mujer), cuya trayectoria personal se alimente de episodios "heroicos", de demostraciones de fervor "patrio", que pruebe sus valores éticos y morales bajo situaciones extremas. Alusivo a este tipo de tendencias, Bell ha señalado que "aunque subsistan la retórica y los símbolos originales, el contenido ha sido sutilmente redefinido a lo largo del tiempo, para justificar los códigos sociales establecidos y los controles sociales que sustentan el poder de la clase dominante" (Bell, 1989: 68).

Para que valga la pena el esfuerzo y construcción de la memoria sobre un pretérito ejemplar, acuden a escena quienes se proclaman herederos virtuales de aquellos "grandes hombres" evocados en el relato histórico. El vínculo se establece a través de ceremonias y rituales cívicos, que en apariencia, están destinados a "honrar" a los "héroes", "pioneros", "forjadores" u "hombres de su época". En el fondo, lo que se produce es un amable cotejo biográfico entre quienes se han erigido en continuadores del legado del prócer homenajeado y este último.

El despliegue de blasones y biografías ejemplares será instrumentado como capital político y moral que contribuya a legitimar posiciones y posesiones personales en el conglomerado social. Al invertirse este capital, redituará rendimientos como el reconocimiento público o bien, servirá para redimirlo del ostracismo social en el que pueda haber caído merced a la ingratitud colectiva. De ser el segundo de los casos, el rescate de los grandes predecesores y del relato histórico, servirá para revertir la ignorancia de las mayorías en cuanto a la "historia local" (a lo cual se achacará la falta de reconocimiento de los herederos de los grandes hombres y sus grandes relatos). Planteamientos así son comunes en una ciudad como Tijuana, construida por migrantes, a quienes siempre se les está cuestionando el "desarraigo" respecto a la tierra que los alberga.

Aldarse por hecho que buena parte de los habitantes de Tijuana no tienen una identificación plena con la ciudad, a raíz de sus diversos orígenes y la movilidad que experimentan, se ponen en juego una serie de medidas dirigidas a "concientizar" a las nuevas generaciones sobre su lealtad y afiliación con la ciudad. Esta clase de objetivos atiende la organización de la "Feria de Historia de Tijuana", realizada por instituciones culturales, académicas y sociales, que se destina a los estudiantes de secundaria. Con ello, pretenden difundir y acercar la historia local a "la juventud tijuanense" para inculcarle "el sentido de pertenencia, identidad y amor a su ciudad"?

En el momento que se busca infundir una filiación identitaria, se privilegia una forma de relato histórico centrada en episodios que reproducen a escala local los ingredientes discursivos de la historia de bronce manufacturada desde el centro del país. Muchos de estos episodios locales responden al cuestionamiento elaborado desde el "epicentro" de la nación, que regatea el grado de "mexicanidad" o lealtad de los ciudadanos fronterizos. A las dudas sobre la fidelidad nacional de los fronterizos originadas luego de la pérdida de territorios en la guerra de 1848 con Estados Unidos, se sumaron viejos argumentos que resaltaban el origen "bárbaro" de los habitantes del septentrión mexicano. En esta tradición encajan frases como la atribuida a José Vasconcelos respecto a que "Sonora es el lugar donde termina la cultura y empieza la carne asada". 
En el plano local, encontramos un singular exponente de este tipo de concepciones en la figura de un personaje llamado Rubén Vizcaíno Valencia, profesor, poeta, periodista, dramaturgo, dibujante y vehemente promotor de las artes y las humanidades en Tijuana. Durante el medio siglo que radicó en Baja California, se dedicó a alertar y tratar de remediar la carencia de "identidad" y "cultura" de sus habitantes. En aras de solucionar lo que concibió como un problema, emprendió una incansable labor por "culturizar" a la población. Uno de sus proyectos consistió en fundar el suplemento cultural "Identidad", que ha sobrevivido y continúa publicándose dominicalmente en el diario El Mexicano.

Hay una anécdota que describe la empresa y talante un tanto quijotesco de este conspicuo personaje:

Los jóvenes [...] siempre cuentan de él, que encontrándose un compañero de su preparatoria en el jardín, pensando tal vez, en la inmortalidad del cangrejo, pasa el maestro Vizcaíno y le dice: no pierdas el tiempo, has poesía (Sandez, 1979: 61).

Al margen de la veracidad o ficción del anterior pasaje, es útil para describir la visión tenida por Vizcaíno sobre la "cultura" y su vehemencia por impulsarla en Tijuana.

Otro de los parámetros que suelen acompañar la noción de identidad en Tijuana es el de ubicarla como un punto distante del "corazón" de la cultura mexicana encarnada en el centro del país. Al carecer de los símbolos que testimonian el lazo con lo "nacional": basamentos piramidales de origen prehispánico (prueba latente de una "gran civilización" que fue uno de los dos afluentes fundadores de la nacionalidad), aguardientes, artesanías, vestimentas y danzas folclóricas "regionales". Gilberto Loyo, pionero de los estudios demográficos en el país e influyente partícipe en el diseño de las políticas poblacionistas del Estado mexicano en las décadas de 1920 y 1930, mirando al norte alguna vez se quejó porque "en grandes zonas del país se hallan poblados donde no existe ni baile regional, ni canción vernácula" (Loyo, 1935: 383).
Tal vez para subsanar esta "carencia", al amparo de las políticas educativas del gobierno cardenista, se promovió la puesta en escena de rituales cívicos tendientes a inculcar la "mexicanidad". En esta tónica, observamos que a propósito del primer desfile conmemorativo de la independencia en 1938, efectuado en el recién fundado ejido El Porvenir en el valle de Guadalupe en el mismo año, entre cuyos miembros habían varias familias repatriadas de Estados Unidos, se representó una estampa de lo "nacional":

[...] iay pues éramos un puñadito de gente! Estaba el profesor Víctor Guirola, un hombre activo, entonces dijo él "vamos a tener reina" [...] Estaba un carrito sin toldo [...] dijeron "bueno, aquí la vamos a pasear", ipor cuáles calles si no había ni gente? [...] Al profesor le gustó que ella fuera porque representaba por su pelo largo, y ella usaba trenzas muy gruesas, dijeron "ella puede representar una mexicana", como no teníamos nada, completamente, hasta el año siguiente empezamos a hacer nuestras faldas de china poblana y las bordábamos con chaquira, lentejuela, hacíamos nuestras camisas y ya decíamos que teníamos fiestas, pero ella fue la primera, una mexicana, una muchacha que se paseara, que vaya encabezando el desfile. ${ }^{8}$

Los lamentos ante la ausencia de prácticas de cuño popular, ensambladas en atuendos folclóricos monumentales acordes a los modelos estimulados y diseñados en el proceso de construcción identitaria de "lo mexicano", 9 fueron incorporados, y con toda seguridad reformulados, entre algunos miembros de la "opinión pública" regional. A fines del decenio de 1970, un antiguo residente de Baja California, abogado de profesión, se regocijaba de que el "desarrollo cultural" en la entidad se incrementara día con día, puesto que al carecer "de tradición, de costumbres propias y en sí de una cultura bajacaliforniana, esto puede ser el comienzo de lo que antaño no tuvimos" (Sandez, 1979: 60). El autor de estas palabras fue parte de las primeras generaciones 
de habitantes de Baja California que emigraron para cursar estudios universitarios, tras lo cual retornaron y participaron activamente en la vida intelectual, política y económica regional.

Los denodados cuestionamientos centralistas hacia los fronterizos por su supuesta "mexicanidad" degradada, encontraron su principal impugnación local a través de las interpretaciones formuladas a propósito de eventos armados desarrollados en Baja California en 1911, en el marco de la lucha revolucionaria. En el caso de Tijuana, esto se concentra en una polémica derivada de la participación en el conflicto de un grupo de pobladores locales, que ese año repelieron la ocupación del poblado a manos de un contingente armado que procedía de Estados Unidos. Desde la ciudad de Los Ángeles, California, Ricardo Flores Magón alentó la incursión a Baja California con propósitos revolucionarios, pero en las filas de este movimiento se incrustaron combatientes con fines distintos y no muy claros, que iban desde los propiamente revolucionarios hasta las pretensiones anexionistas al vecino país del norte, el tema ha sido abordado académicamente desde perspectivas distintas (cfr. Taylor, 2002 y Samaniego, 2009). Con los atacantes había mexicanos y hombres de distintas nacionalidades.

La controversia estriba en que un sector influyente política y económicamente en la ciudad, sostiene e impulsa la versión de que el grupo de vecinos que combatió a los atacantes actuaron en defensa de la integridad del territorio nacional, toda vez que confrontaron a mercenarios y filibusteros. En particular, destacan como partidarios de esta visión los miembros de la Sociedad de Historia de Tijuana, A. C. Entre sus principales iniciativas se cuenta bregar por el reconocimiento oficial y social del pasado heroico de los "tijuanenses", de ahí su lucha porque al nombre de Tijuana se le anteponga el título de "heroica". Autoerigidos en hederemos de los "defensores", se consideran custodios de esta "verdad histórica". Aquél que cuestione su discurso se expone a fuertes descalificaciones, ya sea por mostrar "ignorancia" de la historia local o bien, por su condición de "advenedizo" en la ciudad.

De lado contrario, persisten aquellos que defienden el carácter revolucionario y magonista de los atacantes. Entre estos destacan los miembros de la masonería, integrantes del Partido Revolucionario Institucional (PRI), y militantes de izquierda. Al resaltar la figura de Ricardo Flores Magón, argumentan que el ataque armado era la primera etapa de un plan revolucionario mayor que buscaba liberar a México de la dictadura porfirista.

Al contrario de los sucesos de 1911, que dividen y suscitan polémica entre la opinión pública, los festejos por el aniversario de fundación de la ciudad logran consenso y simpatía. Se trata de la celebración de índole histórica que más entusiasmo atrae actualmente en Tijuana. La manera en que se oficializó una fecha fundacional de la ciudad y la correspondiente necesidad de establecer un relato histórico que lo haga verosímil, la legitimación de un evento que de arranque a la narración configurada sobre el poblado, brindan la posibilidad de analizar con bases empíricas buena parte de lo que hasta aquí se ha planteado en términos generales. La siguiente parte del texto discurre sobre el proceso de surgimiento de Tijuana y deja entrever elementos para indagar a futuro sobre la manipulación que al respecto se hace desde el presente.

\section{El surgimiento de Tijuana}

De forma gradual, la conmemoración de la fundación de Tijuana ha venido ganando espacio en el calendario cívico local al grado que en los últimos años, El Mexicano y Frontera, los dos principales diarios de la ciudad, le dedicaron suplementos especiales, mientras varias estaciones de radio dedican parte de su programación al mismo tema. La creciente aceptación y propagación de este festejo es un fenómeno reciente. En un suplemento especial abocado a esta celebración, el diario Frontera 
hace un recuento de cómo décadas atrás, los periódicos citadinos apenas hacían mención del onomástico. ${ }^{10}$

La designación de una fecha fundacional para Tijuana responde más a criterios institucionales que fácticos. Es el esfuerzo por dotar a la ciudad con un acta de nacimiento. Esto permite forjarle un origen mesurable, aproximado a la noción positiva de "verdad", aunque como reconociera uno de sus cronistas oficiales, no deja de ser una cuestión virtual al no existir "documento formal alguno, que señale la hora, el día, mes y año de su fundación, signado por alguna autoridad". "I

La "fundación” de Tijuana se fijó el ll de julio de 1889. La decisión para determinar oficialmente los inicios urbanos de este poblado se basan en la "resolución judicial que aprobó el convenio que finalizó el juicio intestamentario sostenido entre los herederos de doña Pilar Ortega de Argüello, viuda del primer propietario del rancho, misma que se anotó en el Registro Público de la Propiedad de Ensenada el 11 de julio de 1889, con lo que se pudo efectuar la venta de manzanas y predios en una parte fraccionada del rancho" (Ortiz y Piñera, 1989: XVII).

Una revisión más crítica de dicho documento indica la supeditación del proyecto de fraccionar una porción del rancho Tijuana a la normatividad legal del Estado mexicano, donde al menos desde 1874 existía un asentamiento conformado en derredor de la aduana fronteriza establecida en ese año para fiscalizar el flujo de mercancías entre el Partido Norte de la Baja California y California, Estados Unidos. ${ }^{12}$ El ingeniero Ricardo Orozco, contratado por los propietarios del predio para efectuar el deslinde de terrenos, dejó claro que el naciente fraccionamiento distaría "cinco kilómetros de la actual población". 13

El acuerdo legal del 11 de julio de 1889 se realizó para asegurar la tenencia de la tierra a los herederos del rancho, así como para extraer beneficios económicos por la venta de los predios fraccionados de cara a una eventual expropiación solicitada por los vecinos del primigenio poblado tiempo atrás. Los herederos del rancho optaron por fraccionar el predio, legalizado con un protocolo jurídico, para frenar la presión ejercida por los pobladores que, espontáneamente, se habían ido estableciendo en los alrededores de la aduana fronteriza.

La actividad generada en torno a la aduana atrajo un reducido número de personas que se asentaron en sus inmediaciones para ofrecer servicios como la venta de alimentos, cuidado de animales de tracción o de diversos artículos requeridos por los viajeros que iban de un país a otro. Además, algunos pobladores se empleaban en tareas de labranza y cría de ganado para complementar su subsistencia.

Desde la década de 1880, se manifestó una creciente industrialización junto al avance del ferrocarril que produjo un auge en la venta de bienes raíces en el sur de California, derivado del crecimiento económico y demográfico, a causa de la expansión económica que desde décadas anteriores avanzaba desde la Costa Este hacia la Costa Oeste de Estados Unidos. Consecuencia de lo anterior, fue la edificación de varias ciudades adyacentes a las concentraciones urbanas de San Diego y Los Ángeles, California, dinámica que se conoce como el "Boom de los ochenta", ${ }^{14}$ con repercusiones tardías en las localidades mexicanas de Ensenada y Tijuana (Piñera, 1991).

Para el momento en que se fraccionó una parte del rancho Tijuana, el llamado boom había llegado a su fin en el lado estadounidense de la frontera. Hasta ahora, ha prevalecido la idea de que el acuerdo entre los herederos fue consecuencia única del auge urbanizador experimentado al norte de la frontera. No obstante, sin descartar la influencia de este fenómeno económico, es preciso considerar también los temores de los herederos ante una eventual expropiación. El gradual poblamiento espontáneo al rededor de la aduana explica la decisión de los herederos del rancho Tijuana para conciliar sus intereses y que se decidieran a fraccionar una parte del predio pues incluso se mencionaba que existía la petición de expropiarlos para regularizar los terrenos en torno a la aduana donde se asentaba la población. 
Lo anterior, se sustenta en una petición hecha en 1887 por un grupo de vecinos del rancho de Tijuana al subprefecto del Partido Norte (por entonces máxima autoridad en el norte del Territorio de la Baja California), para ascender de categoría política y pasar de rancho a pueblo. Además, ofrecían pagar una tarifa "justa" por los terrenos que tenían ocupados con el fin de indemnizar a los propietarios legales del rancho. La iniciativa contó con el apoyo del subprefecto político, quien abogó por esta causa ante el gobierno federal. En su alegato, vislumbró que en un tiempo no lejano Tijuana adquiriría mayor importancia, pero que este crecimiento se veía frenado por la inseguridad de los moradores respecto a las propiedades que detentaban. Como solución, el funcionario sugirió expropiar..$^{15} \mathrm{La}$ amenaza de una eventual expropiación contra la familia Argüello debía tomarse en serio.

\section{El imán lúdico-concupiscente}

Durante esta etapa formativa de Tijuana, merced al sesgo económico que comenzó a tener, fue labrándose la imagen de un sitio propicio para realizar actividades lúdicas y concupiscentes. Al cabo de unos años, en los poblados fronterizos adyacentes de lado estadounidense, se habían tejido una serie de discursos afirmativos sobre lo disoluta que se suponía resultaba la vida allende el sur de la frontera. La percepción de Tijuana como una localidad predispuesta para dar y recrear prácticas viciosas, juegos de azar, relaciones venales y tráfico de diferentes mercancías, se gestó en las décadas de 1880 y 1890.

Durante este periodo, se perfilaron como parte puntal de la economía local una serie de ofertas de entretenimiento y recreación enfocadas a atraer consumidores del sur de California. Por esos años, de lado estadounidense se experimentaba un considerable auge económico y demográfico, al mismo tiempo que resonaban las posiciones moralistas sostenidas por autoridades y grupos religiosos en contra de lo que a su parecer envilecía a la sociedad, tales como la embriaguez, la prostitución y el juego.

En vista de que existía un mayor grado de tolerancia de lado mexicano, las actividades económicas implementadas en Tijuana se orientaron a ofrecer servicios que satisficieran los apetitos concupiscentes y lúdicos de los consumidores provenientes del vecino país. Bajo estas condiciones, en el vecino puerto de San Diego, California, se crearon empresas de diligencias que trasladaban a los excursionistas para que pasaran algunas horas o días en Tijuana. Especial atracción causaban los esporádicos eventos que involucraban combates físicos entre animales como corridas de toros y peleas de gallos, o bien, alguna competencia pugilística entre hombres de distintos grupos étnicos. Un aspecto importante a considerar es que una parte de estos establecimientos operaban con capital estadounidense. Incluso su personal era de la misma nacionalidad. Cada fin de semana o en los días feriados en Estados Unidos, cientos de personas cruzaban la frontera para invertir su tiempo libre en la naciente Tijuana.

Aunque la oferta recreativa de lado mexicano conllevaba un estigma social ante la sociedad del sur de California, también llegaban excursionistas al balneario de Agua Caliente, un lugar concebido como refugio para descansar, entrar en contacto con la naturaleza y bañarse en sus aguas termales, las que según se anunciaba, poseían propiedades curativas y terapéuticas. La idea de que la cercanía con la naturaleza y las aguas termales redituaban beneficios corporales, contaba con arraigo en Estados Unidos y Europa. Servía como escaparate a la dureza de la vida moderna concentrada en las manchas urbanas, sujetada a los avances tecnológicos y la creciente transformación ecológica. Si bien, en el sur de California no eran pocos los spas que ofrecían estos servicios, el atractivo ejercido por lo externo, por la sensación de alteridad que suponía trasponer la frontera alentaba el flujo de personas de norte a sur con fines recreativos.

142 Revista LiminaR. Estudios sociales y humanísticos, año 7, vol. VII, núm. 2, diciembre de 2009, Tuxtla Gutiérrez, Chiapas, México. ISSN: 1665-8027 
Bajo estas premisas, a partir de las dos últimas décadas del siglo XIX comenzaron a delinearse los cánones constitutivos de las mutuas percepciones entre los vecinos de uno y otro lado de la frontera. Las tendencias económicas observadas en este lapso corresponden a un proceso de articulación económica del norte de Baja California al sur de California como respuesta a las demandas planteadas por la creciente urbanización y la consecuente necesidad de entretenimiento entre los estadounidenses para explorar nuevas formas y posibilidades de ocio en el lado mexicano.

Había una exigencia por sustraerse a las prohibiciones morales existentes en Estados Unidos, derivadas del movimiento temperante que recorrió ese país a fines del siglo XIX como respuesta a los cambios sociales experimentados por la creciente urbanización y los adelantos tecnológicos ${ }^{16}$ acicateado por el puritanismo religioso (Daniels, 1995). Estos posicionamientos alcanzaron su máxima expresión a partir de 1907 en algunos condados fronterizos de California, y más tarde, se extendió a Estados Unidos en 1919 cuando se promulgó la Ley Volstead, que prohibió la elaboración y consumo de alcohol. Las restricciones respecto a la venta de bebidas alcohólicas y juegos de azar, incentivaron la apertura de negocios de esa naturaleza en Tijuana desde el primer decenio del siglo XX. ${ }^{17}$

La colindancia con territorio mexicano se explotó al posibilitar el acceso a los placeres prohibidos o poco tolerados dentro de las leyes y cánones morales estadounidenses. En el sur de la frontera se podían sustraer de los obstáculos que limitaban el disfrute del ocio. Esto incluía la satisfacción de las pulsaciones lúdicas y concupiscentes.

Trasponer la frontera implicaba la idea de acceder a lo extraño, el pasaporte a un mundo exótico donde la civilización entendida como progreso y modernización estaba ausente. No en balde, en múltiples ocasiones aparecieron señalamientos en el sur de California acerca de la "degeneración" de los actos cometidos de lado mexicano. Por añadidura, lo que ahí acontecía se veía como reflejo del estado cultural de una sociedad capaz de generar espectáculos de barbarie como las corridas de toros y las peleas de gallos.

Existe en esta percepción sobre el otro, una anteposición entre dos culturas vecinas, una relación de poder que genera resistencias en ambos sentidos, con ello se produjo un proceso de miradas encontradas y complementarias en la autodefinición de los contornos de cada una de las partes. Entre las dos entidades culturales se gestó una interacción que hizo viable la toma de posición respecto a las prácticas culturales del vecino. Así, se abrió el camino para las clasificaciones y estereotipos con los que se pudo familiarizar la aceptación de lo propio a costa de rechazar lo ajeno.

Dentro de la perspectiva de las autoridades y diversos sectores sociales del sur de California, Tijuana fue configurada como un espacio de desmanes y placeres prohibidos, evidente manifestación de un pueblo atrasado y sin ley. En cambio, de lado mexicano las autoridades y vecinos "principales" exigieron frenar los excesos cometidos por los estadounidenses, en su mayoría varones, que cada fin de semana o días festivos acudían a embriagarse y comportarse de manera escandalosa por las calles del poblado.

\section{Orígenes de la oferta recreativa}

Fue en las décadas de 1880 y 1890 cuando florecieron establecimientos dedicados a juegos de azar como el tiro al blanco y el fish pound (que consistía en atrapar peces dentro de un estanque); a la par de corridas de toros, peleas de gallos y funciones de box. Buena cuenta del desagrado que ello provocaba en políticos y religiosos del lado estadounidense quedó reseñada en las notas informativas y editoriales de los periódicos editados de uno y otro lado de la frontera. La percepción de Tijuana como un imán lúdico-concupiscente, una entidad dotada con cierta fuerza magnética capaz de atraer a su radio de influencia a aquellos que buscaban opciones para salvar lo proscrito moralmente en su 
país, se había puesto en marcha. Como respuesta, en Tijuana se manifestaron inconformidades por la mala imagen que proyectaba la localidad en Estados Unidos, a la vez, se expresaba el disgusto por los desmanes que los visitantes provocaban cada fin de semana o día festivo. La perspectiva de decadencia sobre la población de Tijuana había sido planteada desde 1882, cuando se buscó atacar los vicios sociales mediante la educación. Por ello, la segunda institución de gobierno después de la aduana fue una escuela elemental dispuesta para atender a los niños mexicanos, los cuales en su mayoría residían en el poblado contiguo de Tía Juana, California. ${ }^{18}$

La decisión de cambiar el uso del suelo, de transformar parte de un predio rural en un espacio urbano, simbolizó el apuntalamiento en la frontera septentrional de Baja California de la estructura económica extendida a lo largo del siglo XIX en Estados Unidos desde la costa atlántica al Pacífico. En el sur de California el proceso de afianzamiento del capitalismo se manifestó de forma tangible a través de la explotación minera y las vías del ferrocarril de carga y pasaje, que conectaron esa región con el medio Oeste, lo que dio lugar a fenómenos como el auge en la venta de bienes raíces.

La apertura de nuevas tierras a la colonización permitió que en las periferias de San Diego y Los Ángeles, California, se proyectaran pequeñas ciudades con un enorme despliegue publicitario cargado de mensajes que ponderaban la amabilidad del clima, la fertilidad del suelo, la disponibilidad de vías de comunicación y las oportunidades para realizar negocios. Un alto porcentaje de los colonizadores eran hombres, quienes al devengar mejores salarios que en sus lugares de procedencia, al lidiar con la soledad y la necesidad de espacios donde mitigar sus nostalgias y gastar su ocio, se refugiaron en cantinas y garitos en los que podían tentar a la fortuna mediante apuestas.

Por otro lado, un número de familias de mayor posición económica como comerciantes, burócratas o profesionistas que seguían un modelo de vida burgués, se abocaron a las excursiones que los transportaban a ambientes naturales y exóticos que les prodigaban salud. Por un breve periodo, atravesaban los límites de la "civilización" para llegar al "Old México", el cual se encargaban de promover los periódicos, revistas y tarjetas postales producidos por las empresas de diligencias y del tren ligero que operaban estos paseos y tenía como base San Diego, California.

$\mathrm{Al}$ menos desde 1880 funcionaba un balneario de aguas termales en el paraje de Agua Caliente, distante unos kilómetros al Este del poblado de Tijuana, bajo administración estadounidense. ${ }^{19}$ Dos años después, ya se había edificado un modesto hotel e instalaciones adecuadas para los baños. ${ }^{20}$ Los excursionistas eran trasladados de San Diego al balneario, por un servicio de carros de tracción animal que hacía el tornaviaje tres días a la semana. ${ }^{21}$ También se promocionaban excursiones a "El Monumento", como se conocía el punto donde se ubicaba la mojonera número 258 que dividía México y Estados Unidos. La publicidad lo señalaba como propicio para paseos campestres dada su proximidad al mar. ${ }^{22}$ Respecto al poblado de Tijuana, se anunciaban visitas a la única calle existente, sobre la cual se alineaban los comercios de souvenirs, cantinas y garitos. ${ }^{23}$

Una fotografía tomada en 1890 [Foto 1], deja ver la afluencia de visitantes al momento de atravesar el río situado de lado mexicano a unos metros de la garita entre ambos países. Se aprecian al menos cinco vehículos tirados por caballos que llevan a decenas de excursionistas con dirección a Tijuana, mientras que en los carros que retornan a Estados Unidos van sin pasajeros. En junio de 1888, fue concluida la línea ferroviaria "National City and Otay Railway" que enlazaba por tren al puerto de San Diego con las poblaciones cercanas a la frontera con México, en particular Tía Juana, cuya estación de ferrocarril se encontraba a escasos pasos de la línea divisoria con Tijuana (Padilla, 1998: 134). Más tarde, una vía de tren ligero fue extendida hasta la calle del poblado mexicano. 


\section{Visitantes non gratos}

En mayo de 1886, el administrador de la aduana de Tijuana, principal representante del gobierno federal en la localidad, se quejaba ante el subprefecto del Partido Norte (a su vez dependiente del gobernador del territorio con sede en La Paz, Partido Sur), del tipo de visitantes que recibía la localidad:

[...] muchos se abstienen de hacer el tráfico por esta frontera por temor de encontrarse con la chusma de ebrios escandalosos que constantemente pululan en esta población, insultando a todo el que se les presenta por delante. Anoche a las doce un puñado de hombres ebrios vitoreaba a los Estados Unidos y proferían mueras a México [...] en vista de las indiferencia de las autoridades; qué se puede esperar, cuando con su silencio se les tolera para que cometan unas tropelías de las que se han estado cometiendo hasta hoy. ${ }^{24}$

Elfuncionario aduanal disponía de un cuerpo armadocompuesto por vistas aduanales, manejaba los recursos económicos obtenidos del cobro de aranceles a las mercancías en tránsito por la frontera. Tales atribuciones le conferían autoridad en el poblado. Si nos atenemos al discurso esgrimido por este funcionario federal, se evidencia la mezcla de sentimientos nacionalistas que fustigan al visitante extranjero al tiempo que recriminan al habitante fronterizo su falta de "mexicanidad". Asimismo, está latente el enjuiciamiento moral sobre las aficiones atemperantes de los visitantes estadounidenses y la disputa por los espacios de poder local basadas en consideraciones económicas. Respecto a esto último, existía preocupación en las esferas del poder político local sobre las consecuencias que el desorden producido por los visitantes pudiera causar en el desarrollo comercial de Tijuana, pues con ello, afectaría la recaudación de impuestos fuente de recursos para las arcas federales. También se trasluce una crítica contra el juez de paz, personaje en quien el administrador aduanal quizá veía competencia a su autoridad.
En una segunda imagen que data de 1887, [Foto 2] se aprecia el papel preponderante de la aduana en el poblado. Para ese tiempo, el cuadro urbano de Tijuana se reducía a una serie de construcciones de madera, casi todas de un solo nivel entre las cuales mediaban varios lotes baldíos. En la referida fotografía, se ubica al fondo la única obra con pretensiones arquitectónicas menos sobrias, cuyas dimensiones, tamaño y color claro sobresalen con relación al resto de los edificios. Encima, se eleva a varios metros el asta bandera, como reforzando el estatus principal del edificio federal, la cual es coronada por una bandera mexicana ondeante, dispuesta para reafirmar el orgullo patrio ante el constante sentimiento de amenaza que suscita el vecino país. Tanto el discurso del jefe aduanal como la bandera, simbolizan toda una concepción centralista de México, que achaca a los pobladores fronterizos cierto desarraigo y carencia de "mexicanidad".

Conforme se acercaba el siglo XX, la oferta de espectáculos fue diversificándose. En 1888 inició operaciones un local construido sobre la línea divisoria entre los dos países. El establecimiento pertenecía a un estadounidense; aunque se denominaba "plaza de toros" tenía usos múltiples al servir de sede a peleas de gallos, aunado a que según una nota periodística, se pensaba realizar una competencia atlética entre los mejores corredores californianos (anglosajones) contra los corredores indios de la región. ${ }^{25}$ La operación de este sitio generó la protesta del jefe político del Distrito Norte, quien indicó que la mayor parte de la construcción estaba del lado mexicano y sólo una mínima porción, aquella correspondiente a las gradas, se situaba de lado estadounidense, puesto que en ese país los espectáculos taurinos estaban prohibidos. El funcionario adujo que la razón de ubicar en ese punto el establecimiento era porque el exceso de alcohol producía frecuentes peleas, y para evadir la acción de la justicia, los rijosos se pasaban de un lado a otro del ruedo donde eran hostigados por la fuerza pública. De ese modo, escapaban a la policía mexicana o estadounidense. ${ }^{26}$ Sin embargo, pese a la queja, el jefe 
político no evitó un pronunciamiento optimista sobre el poblado: "Tijuana se encuentra situado en la línea divisoria y confundido, puede decirse, con el pueblo de Tía Juana de los Estados Unidos, pues sólo están separados el uno del otro por una línea imaginaria y ambas poblaciones están levantándose con bastante rapidez". ${ }^{27}$

La descripción del tipo de espectáculos programados en este coso taurino binacional proporciona una abertura para entender algunas convenciones sociales y culturales predominantes en esa zona de frontera. La carrera atlética en este caso serviría como arena de confrontación para medir las capacidades físicas entre seres semejantes en lo biológico, pero diferentes culturalmente. La prueba deportiva entre anglosajones e indios hacía constar las discrepancias. Al margen del resultado, se distinguía al hombre civilizado de los bárbaros.

Era el tiempo en que ganaban prestigio las teorías antropológicas de cuño alemán que negaban todo principio de divergencia biológica entre los grupos humanos pero reconocían que las distinciones se daban en el orden cultural. La programada carrera, que al parecer no se llevó a cabo, tuvo un significado alegórico respecto al concepto decimonónico de frontera, entendida ésta como un campo abierto a la colonización, un escenario de contacto entre dos sociedades inscritas dentro de relaciones verticales. Por otra parte, las constantes condenas de las autoridades mexicanas al "excesivo consumo de alcohol", reproducían una preocupación compartida por la clase política liberal, quienes veían en el alcoholismo un lastre social degradante para las masas, relacionado con el aumento de la criminalidad (Delgado, 2000: 244). ${ }^{28}$

Debe tenerse en cuenta que en la transición finisecular del XIX al XX, las ideas temperantes cobraron auge en el mundo. ${ }^{29}$ En Estados Unidos estos posicionamientos fueron más firmes, al grado de que se prohibió la producción y consumo de alcohol entre 1919 y 1933. Una de las primeras regiones en asumir estas prohibiciones fue el sur de California. ${ }^{30}$ Los grupos prohibicionistas estaban integrados por sectores religiosos, empresariales, gobernantes y educadores (Gómez, 2005: 34).

Por lo regular, a estos grupos temperantes, custodios de los valores sociales de la emergente burguesía, les escandalizaba el comportamiento de las clases trabajadoras, aglutinados en tugurios que contravenían las prescripciones sobre higiene, salubridad y buenos modales, y quienes se creía, estaban prestos a la promiscuidad y el ejercicio criminal. Se trataba de un intento de reafirmar el poder sobre aquellos sectores que sujetos a una dura vida laboral y vida depauperada, actuaban dentro de los estrechos márgenes sociales y políticos donde tenían autonomía.

Los trabajadores contaban entonces con la capacidad de decidir cómo y en qué gastar su salario. Elegir dónde divertirse y solazarse para escapar ilusoriamente de la difícil vida citadina y sopesar la distancia del terruño y la familia. Esta era la situación de miles de hombres jóvenes que se trasladaron al meridiano californiano para unirse a la fuerza de trabajo que requerían las labores ferroviarias, la apertura de campos a la agricultura y la imparable urbanización e industrialización en torno a Los Ángeles y San Diego, California. La elección individual para asistir a un establecimiento en los ratos de ocio y dejar ahí parte del producto de su trabajo podría verse como un acto de escapismo. Acceder al margen de autonomía que el individuo gozaba en un sitio público desaprobado socialmente le brindaba posibilidades de relajación, matizado por el efecto desinhibidor de las bebidas alcohólicas, la excitación de la libido o el consumo de sustancias que trastornaban los sentidos fisiológicos y los llevaban eventualmente a apartarse de las conductas convencionales.

Imágenes como las de dos estadounidenses que despreocupados, reposan de pie junto a la barra de una cantina al aire libre atendida por un dependiente mexicano, con unos anaqueles llenos de botellas al fondo, refuerzan la noción de que estar en Tijuana, significaba trasponer la frontera hacia la displicencia. 
[Foto 3] Para afirmar el toque inveterado de que se asiste al Old Mexico, un borrico complementa la escena. Es la prueba de una realidad asequible a los residentes del progresista puerto de San Diego con sólo trasponer la frontera unas millas al sur.

\section{Conclusión}

Ya fueran potenciales excursionistas en busca de contactar con la naturaleza, visitantes que evadían las regulaciones morales en su país, empresas de carruajes dispuestas a transportar a unos y otros, pequeños capitales invertidos en negocios que atendían esas demandas de esparcimiento o vecinos molestos por el tipo de visitantes recibidos y sus contrapartes a disgusto con las opciones de recreación brindadas a sus conciudadanos. Todo ello, conformó la atmósfera lúdico-concupiscente que delineo la imagen representativa de Tijuana. Esto dio lugar a un conjunto de imágenes reforzadas durante el siglo XX. En sentido contrario, emergieron respuestas de tendencias asépticas que intentaron revertir esos imaginarios sociales mediante el fomento de tradiciones y propuestas identitarias sustentadas en una lectura tergiversada del pasado que dieran nuevos sentidos a la historia de una ciudad cuyo crecimiento demográfico se ha caracterizado por su explosividad e irregularidad.

\section{Notas}

${ }^{1}$ Véase el ensayo "Tijuana: puerto libre, casa de todos" incluido en la compilación del mismo autor citada en la bibliografía.

${ }^{2}$ Una exposición de los motivos que animaron este proyecto artístico que resalta las características y condiciones "multiculturales" y "binacionales" de Tijuana puede leerse en un texto autoría de su promotor y patrocinador Antonio Navalón (2004).

${ }^{3}$ Con el advenimiento de la Modernidad "el Estado cada vez definía con mayor precisión el amplio escenario en el que se escenificaban las actividades cruciales que de- terminaban las vidas de los hombres en tanto súbditos y en tanto ciudadanos", en Hobsbawm (2001: 4).

${ }^{4}$ Para un estudio de caso en que se plantea como el manejar un ideal de comunidad resulta un elemento importante para configurar identidades y acceder o mejorar posiciones hegemónicas dentro de un ámbito local, y a su vez otorga mayores capacidades de negociación con sectores externos, véase Uzeta (1999).

${ }^{5}$ Hago estas últimas consideraciones a partir de lo planteado para el caso europeo de fines del siglo XIX en Hobsbawm (op. cit., p. 3).

${ }^{6}$ Véase entrevista a Renato Ortiz en Link (2000).

7 "Presentación", $4^{a}$ Feria Tijuana en la Historia, suplemento especial de El mexicano, Tijuana, abril de 2008: 3.

${ }^{8}$ Entrevista a Silvia Lugarda Enríquez, en "Festividades en el ejido El Porvenir: la patria y la cosecha de uva", (Samaniego, 1999: 679-680).

${ }^{9}$ Una breve exposición al respecto se halla en Pérez Montfort, "Una región inventada desde el centro. La consolidación del cuadro estereotípico nacional, 1921-1937" (1994: 113-148).

10 "Mínimos festejos", Frontera, suplemento especial del 116 aniversario de la fundación de Tijuana, 11 de julio del 2005: 5.

${ }^{11}$ Mario Ortiz Villacorta, "l16 años de Tijuana", en Frontera, 11 de julio de 2005: 22.

${ }^{12}$ Establecimiento de una aduana fronteriza en Tijuana, Partido Norte de la Baja California, México, 1874, AGN, Gobernación, 1874: 4, vol. 586, sección s/s exp. 7, en IIH$\mathrm{UABC}$ [13.19].

${ }^{13}$ Medición y avalúo del predio de Tijuana, Ensenada, 1889, Archivo General de la Nación (AGN), Dirección General de Gobierno, 2382(30)24554, t. II, caja 70, exp. 20/1, Instituto de Investigaciones Históricas-Universidad Autónoma de Baja California (IIH-UABC) [27.35].

${ }^{14}$ Para una revisión crítica sobre el impacto y alcances reales del llamado "Boom de los 80", véase Ricci (1993: 263-301).

${ }^{15}$ Solicitud de vecinos de Tijuana para que se eleve el lugar a la categoría de pueblo, AGN, Gobernación, Ti- 
juana, 1887, vol. 219 secc. 2ª $887(5)$ exp. 3, 1887.44, en IIH-UABC.

${ }^{16}$ Aunque Jacques Dugast escribió sobre el caso europeo, los siguientes señalamientos bien pueden aplicarse al fenómeno producido en el sur de California durante el último tercio del siglo XIX: "Los progresos de la urbanización y las nuevas condiciones de vida logradas por la industrialización también tuvieron como consecuencia, en las grandes ciudades de Europa, una transformación progresiva de la noción misma de ocio [... En pocos años se había formado un público potencial para formas de actividad inéditas que muy pronto se iban a considerar como paradigmáticas de la cultura moderna." (2003: 91).

${ }^{17}$ Más tarde, durante la Segunda Guerra Mundial, la economía del lado mexicano de la frontera tuvo un repunte notable al amparo de las necesidades de distracción de los militares acantonados en la base naval de San Diego, California.

${ }^{18}$ The San Diego Union, en colección Donald Chaput, IIHUABC, 25 de agosto de 1880 y l de noviembre de 1882 .

19 "Local news. Tia Juana hot springs", en The San Diego Union en colección Donald Chaput (SDU-DC), IIHUABC, 4 de agosto de 1880.

${ }^{20}$ SDU-DC, 19 de agosto de 1882.

${ }^{21}$ SDU-DC, IIH-UABC, 5 de agosto de 1880.

${ }^{22}$ SDU-DC, 17 de octubre de 1880.

${ }^{23}$ Véase ediciones SDU-DC, correspondientes al 5 de agosto y 17 de octubre de 1880: 25 de junio de 1881: 25 de mayo de 1882: 25 de marzo y 11 de septiembre de 1883 y 22 de enero de 1886.

${ }^{24}$ Denuncia del administrador de la aduana de Tijuana al subprefecto del Partido Norte sobre intentos de una invasión filibustera, AGN, Aduana de Tijuana, Tijuana, 1886, en IIH-UABC.

25 "Tia Juana's bull pen", en Los Ángeles Times en Col. Donald Chaput, IIH-UABC, 16 de abril de 1888.

${ }^{26}$ El jefe político pide autorización para trazar en Tijuana una calle ancha paralela a la línea divisoria, AGN, Gobernación, Ensenada, 1888, en IIH-UABC [27.35].
${ }^{27} \mathrm{Ibíd}$.

${ }^{28}$ Todavía en la década de 1920 líderes revolucionarios como el general Salvador Alvarado, (que ocupo la gubernatura de Yucatán entre otros cargos), consideraban un "vicio social" el consumo de alcohol. Inspirado en los movimientos temperantes de Estados Unidos, se pronunciaba por un "país seco", además de proponer el destierro de "lacras sociales" como los juegos de azar, las corridas de toros y las peleas de gallos. (Alvarado, 1985: 265).

${ }^{29}$ Para un recuento sucinto sobre las implicaciones ideológicas y actividades de los movimientos de templanza estadounidenses, así como las reacciones contra éstos en la transición del siglo XIX al XX véase Bell, op. cit., pp. 71-74.

${ }^{30}$ En el Valle Imperial vecino del poblado de Mexicali, la prohibición del consumo y elaboración de alcohol data de 1907 (véase Samaniego, 1998: 48).

\section{Bibliografía}

Alvarado, Salvador (1985), La reconstrucción de México, INEHRM, 3 tomos, colección Biblioteca de obras fundamentales de la Independencia y la Revolución, México, Edición facsimilar del original publicado en México (1919), subtitulada "Un mensaje a los pueblos de América”, J. Ballesca y Cía.

Anderson, Benedict (2005), Comunidades imaginadas. Reflexiones sobre el origen y la difusión del nacionalismo, colección Popular: 498, México: F.C.E. ,

Arensberg, Conrad M. (1961), "The Community as Object and as Sample”, en American Anthropologist, vol. 63, núm. 2 (la parte), New Series, pp. 241-264.

Bell, Daniel (1989), Las contradicciones culturales del capitalismo, colección Los Noventa, número 6, México: Conaculta-Alianza Editorial Mexicana.

Billig, Michael (1998), "El nacionalismo banal y la reproducción de la identidad nacional”, enero-marzo, vol. 60, núm. 1, México: Revista Mexicana de Sociología, pp. $37-57$. 
Chartier, Roger (2005), El mundo como representación. Estudios sobre historia cultural, Barcelona: Gedisa.

Daniels, Bruce C. (1995), Puritans at play. Leisure and recreation in colonial New England, Nueva York: St. Martin's Griffin.

Delgado Aguilar, Francisco Javier (2000), Jefaturas políticas. Dinámica política y control social en Aguascalientes, 1867-1911, Aguascalientes: Universidad Autónoma de Aguascalientes.

Dugast, Jacques (2003), La vida cultural en Europa entre los siglos $X I X$ y $\chi \chi X$, Barcelona: Paidós.

Foucault, Michel (2002), Hay que defender la sociedad, México: F.C.E.

Foucault, Michel (1984), Las palabras y las cosas. Una arqueología de las ciencias humanas, Barcelona: Editorial Planeta.

Gómez Estrada, José Alfredo (2002), Gobiernos y casinos. El origen de la riqueza de Abelardo L. Rodríguez, colección Historia urbana y regional, México: UABC/Instituto Mora.

Hobsbawm, Eric J. (2001), "La producción en serie de tradiciones: Europa, 1870-1914”, en Historia social, vol. III, núm. 4l, Valencia, pp. 3-38.

Krotz, Esteban (2002), La otredad cultural entre utopía y ciencia. Un estudio sobre el origen, el desarrollo y la reorientación de la antropología, México: UAM/FCE.

Larraín, Jorge (2008), El concepto de ideología. El marxismo posterior a Marx: Gramsci y Althusser, colección Escafandra, vol. 2, Santiago de Chile: Editorial Lom.

Link, Daniel (2000), "Modernidad y memoria", en Página 12, suplemento "Radar libros", 3 de septiembre de 2000, Buenos Aires, http://www.paginal2.com. ar/2000/suple/libros/00-09/00-09-03/nota3.htm. [12 de noviembre de 2008].

Loyo, Gilberto (1935), La política demográfica de México, México: Secretaría de Prensa y Propaganda del Partido Nacional Revolucionario.

Möller, Claudia (2008), "La historia moderna y algunos de susconceptos-clave:apuntesentornoaunseminariode Roger Chartier en la universidad de Buenos Aires", en http://clio.rediris.es/tiemposmodernos/articulos/
Numero2-2001-ISSN-1139-6237/mollerl.htm. [12 de noviembre de 2008].

Navalón, Antonio (2004), "La Tercera Nación”, en Nexos, núm. 323, noviembre, México.

Ortiz Figueroa, Jesús y David Piñera Ramírez (coord.) (1989), Historia de Tijuana. Edición conmemorativa del centenario de su fundación 1889-1989, Tijuana: UABC/ Gobierno del Estado de Baja California, XII Ayuntamiento de Tijuana.

Padilla Corona, Antonio (1998), Inicios urbanos del norte de Baja California: influencias e ideas, 1821-1906, Mexicali: UABC.

Pérez Montfort, Ricardo (1994), "Una región inventada desde el centro. La consolidación del cuadro estereotípico nacional, 1921-1937”, en Estampas de nacionalismo popular mexicano. Ensayos sobre cultura populary nacionalismo, México: CIESAS.

Piñera Ramírez, David (1991), Los orígenes de Ensenada y la política nacional de colonización, Tijuana: UABC-Gobierno del Estado de Baja California, Grupo Cultural Septentrión.

Ricci Lothrop, Gloria (1993), "The boom of the "80s revisited", en Southern California Quaterly, vol. LXXV, núm. 3-4, Los Ángeles, California: Historical Society of Southern California, pp. 263-301.

Roucek, Joseph S. (1963), "Historia del concepto de ideología”, en Revista Mexicana de Sociología, vol. 25, núm. 2, mayo-agosto de 1963, México, pp. 665-694.

Rumford, Chris (2006), "Theorizing Borders", en European Journal of Social Theory, vol. 9, núm. 2, Londres: Sage Publications, California-Nueva Delhi, LondresThousand Oaks, pp. 155-169.

Samaniego López, Marco Antonio (2009), Nacionalismo y revolución: los acontecimientos de 1911 en Baja California, Mexicali: UABC/ICBC.

Samaniego López, Marco Antonio (1999), Ensenada. Nuevas aportaciones para su historia, Mexicali: UABC.

Samaniego López, Marco Antonio (1998), Los gobiernos civiles en Baja California, 1920-1923, Mexicali: UABC/ $\mathrm{ICBC}$. 
Sandez Parma, Rodrigo (1979), Nosotros los bajacalifornianos, México: Roto Punto Color.

Scott, James C. (2000), Los dominados y el arte de la resistencia. Discursos ocultos, colección Problemas de México, México: Era.

Smith, Anthony D. (1998), "Conmemorando a los muertos, inspirando a los vivos. Mapas, recuerdos y moralejas en la recreación de las identidades nacionales", en Revista Mexicana de Sociología, enero-marzo, vol. 60, núm. 1, México: UNAM, pp. 61-80.

Stolcke, Verena (2000), "La 'naturaleza de la nación”, en Desarrolloeconómico, abril-junio, vol. 40, núm. 157, Buenos Aires, pp. 23-43.
Taylor Hansen, Lawrence Douglas (2002), "La revuelta magonista al inicio de la revolución magonista”, en Catalina Velázquez Morales, Baja California: un presente con historia, tomo 1, Mexicali: UABC, pp. 303-337.

Trevignani Gagneten, Virginia (2004), La construcción de comunidad como utopía y como distopía, México: FLACSO/Plaza y Valdez.

Trujillo Muñoz, Gabriel (2005), La cultura bajacaliforniana yotros ensayos afines, Tijuana: CECUT.

Uzeta, Jorge (1999), "Comunidad, Estado y agroindustria en Santa Ana Pacueco, Guanajuato”, en Eduardo Zárate Hernández, Bajo el signo del Estado, Zamora, Michoacán: COLMICH, pp. 75-94. 


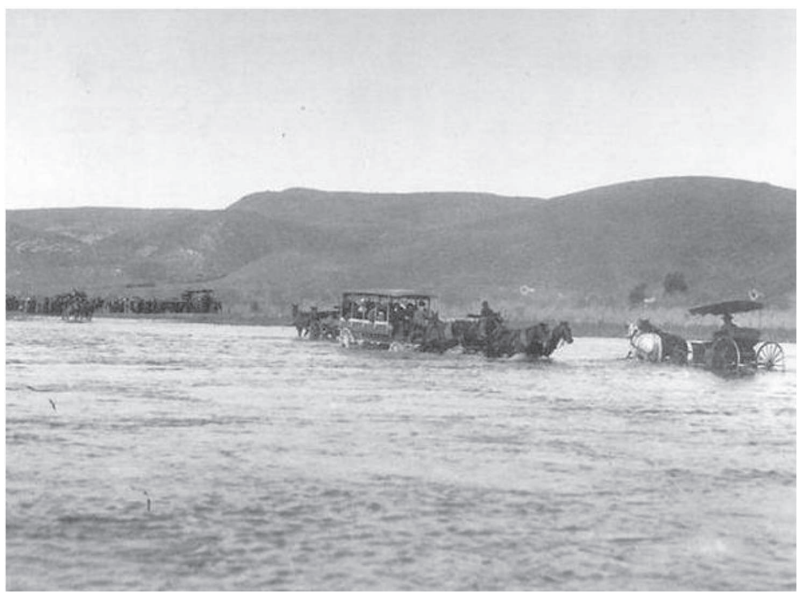

Foto 1

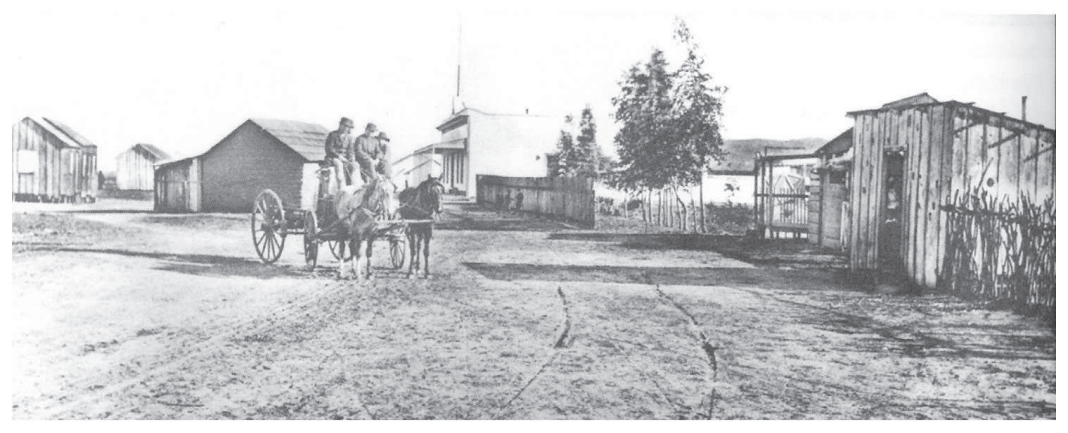

Foto 2

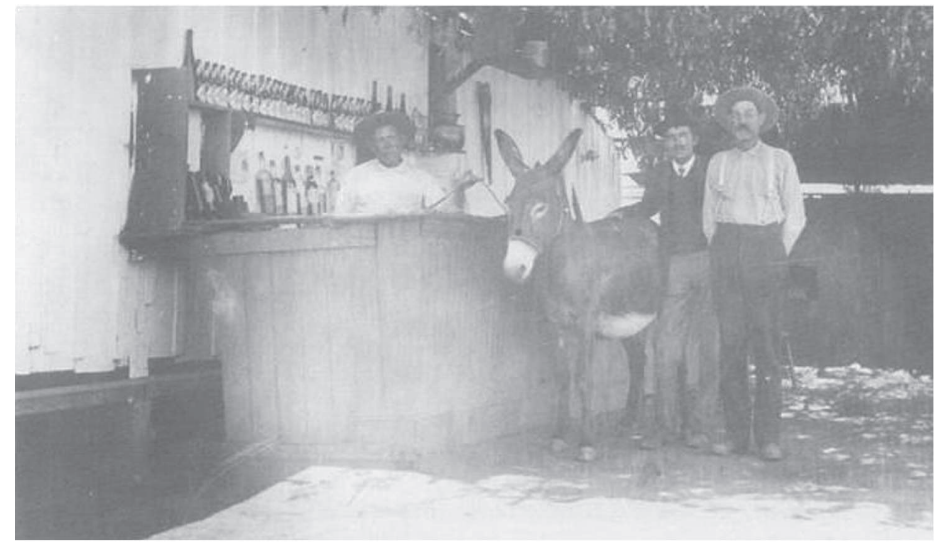

Foto 3

Revista LiminaR. Estudios sociales y humanísticos, año 7, vol. VII, núm. 2, diciembre de 2009, Tuxtla Gutiérrez, Chiapas, México. ISSN: 1665-8027 